\title{
MEASUREMENTS OF HYSTERESIS VALUES FROM HIGH MAGNETIZING FORCES
}

\author{
By W. L. Cheney
}

\section{CONTENTS}

Page

I. Introductory $\ldots \ldots \ldots \ldots \ldots \ldots \ldots \ldots \ldots \ldots \ldots \ldots \ldots \ldots \ldots \ldots, 28 \mathrm{I}$

II. Apparatus. . . . . . . . .

III. Previous method for measuring hysteresis constants $\ldots \ldots \ldots \ldots \ldots \ldots \ldots, 282$

IV. Possible causes of errors in reading.......................... 284

V. Present method for measuring hysteresis constants............... 285

VI. Summary....................................... 289

\section{INTRODUCTORY}

In general, experimenters using various modifications of the "isthmus method" have not been very successful in measuring hysteresis values. Ewing, who first developed the isthmus method, ${ }^{1}$ used an entirely different method for measuring hysteresis values.

Campbell and Dye ${ }^{2}$ describe a method for measuring the residual induction and the coercive force, but they do not publish any hysteresis data in their paper, hence no conclusions can be drawn regarding the value of the method.

The writer $^{3}$ in describing a method (a modification of the "isthmus method") suitable for the measurement of the normal induction of straight bars in intense magnetic fields, discussed also an attempt (not altogether successful) to measure hysteresis values. He has since improved his method so that more satisfactory results may be obtained. The purpose, therefore, of this paper is a description of this method.

\section{APPARATUS}

The apparatus consists essentially of a du Bois electromagnet with flat pole pieces separated by an air gap and pierced coaxially so that a rod may be extended through them and the electro-

1 Ewing, Magnetic Induction in Iron and Other Metals.

- Campbell and Dye, Inst. of Elec. Eng. Journ., 54, p. 35; 1918.

B. S. Scientific Papers, 15, p. 629; 1920. 
magnet. Surrounding the specimen are three coaxial test coils wound on brass forms. When the inner coil is connected in series with a ballistic galvanometer, the normal induction is measured by the throw of the galvanometer upon complete reversal of the magnetizing current. After connecting either the inner and middle or middle and outer coils in series opposition, the value of the magnetizing force can also be determined ballistically.

By careful comparisons with normal induction data obtained on a standard apparatus it was found that the method yielded very satisfactory results. For hysteresis measurements, however, the method was not so successful.

\section{PREVIOUS METHOD FOR MEASURING HYSTERESIS CONSTANTS}

The specimen was magnetized with a force $H_{\mathrm{m}}$ (Fig. I), the corresponding induction $B_{\mathrm{m}}$ being shown at the tip of the hysteresis loop. On complete reversal of the direction of the current in the electromagnet, the magnetizing force changed from $H_{\mathrm{m}}$ to $-H_{\mathrm{m}}$ and hence the induction changed from $B_{\mathrm{m}}$ to $-B_{\mathrm{m}}$. If, then, instead of reversing the current, the circuit was suddenly broken, $H$ should have dropped to zero and $B$ should have changed from $B_{\mathrm{m}}$ to $B_{\mathrm{r}}$. It was found, however, that, on account of the small residual magnetism remaining in the core of the electromagnet, $B_{\mathrm{r}}$ was not quite reached, but instead a somewhat higher value $B_{\mathrm{a}}$. For magnetically hard material $B_{\mathrm{a}}$ differs only slightly from the true value of the residual induction $B_{\mathrm{r}}$, but for softer materials, having a greater slope of the hysteresis curve in this region, the discrepancy is greater.

The coercive force was determined in the following manner: The galvanometer was connected in series with the $B$ coil and instead of completely reversing the magnetizing field $H_{\mathrm{m}}$ it was reduced (by adding a resistance $R_{\mathrm{c}}$ to the primary circuit simultaneously upon reversal of the current) to a small negative field $H_{0}$ which was just sufficient to cause the induction to appear to change from $B_{\mathrm{m}}$ to $O$; that is, the galvanometer deflection was just onehalf the total deflection corresponding to a change from $B_{\mathrm{m}}$ to $-B_{\mathrm{m}}$.

Then, after connecting the galvanometer to either set of $H$ coils and suddenly breaking the circuit, a reading was obtained which corresponded to a change of $H$ from $H_{\mathrm{c}}$ to approximately zero, and was considered proportional to the coercive force. It was difficult to read the deflection very accurately in the case of mag- 
netically soft materials owing to the small order of magnitude of the throw of the galvanometer which is hardly sensitive enough for such small values.

This method is essentially the same as that described by Campbell and Dye. ${ }^{4}$ By comparison with data obtained with the Burrows permeameter ${ }^{5}$ and with the Fahy Simplex permeameter, ${ }^{c}$

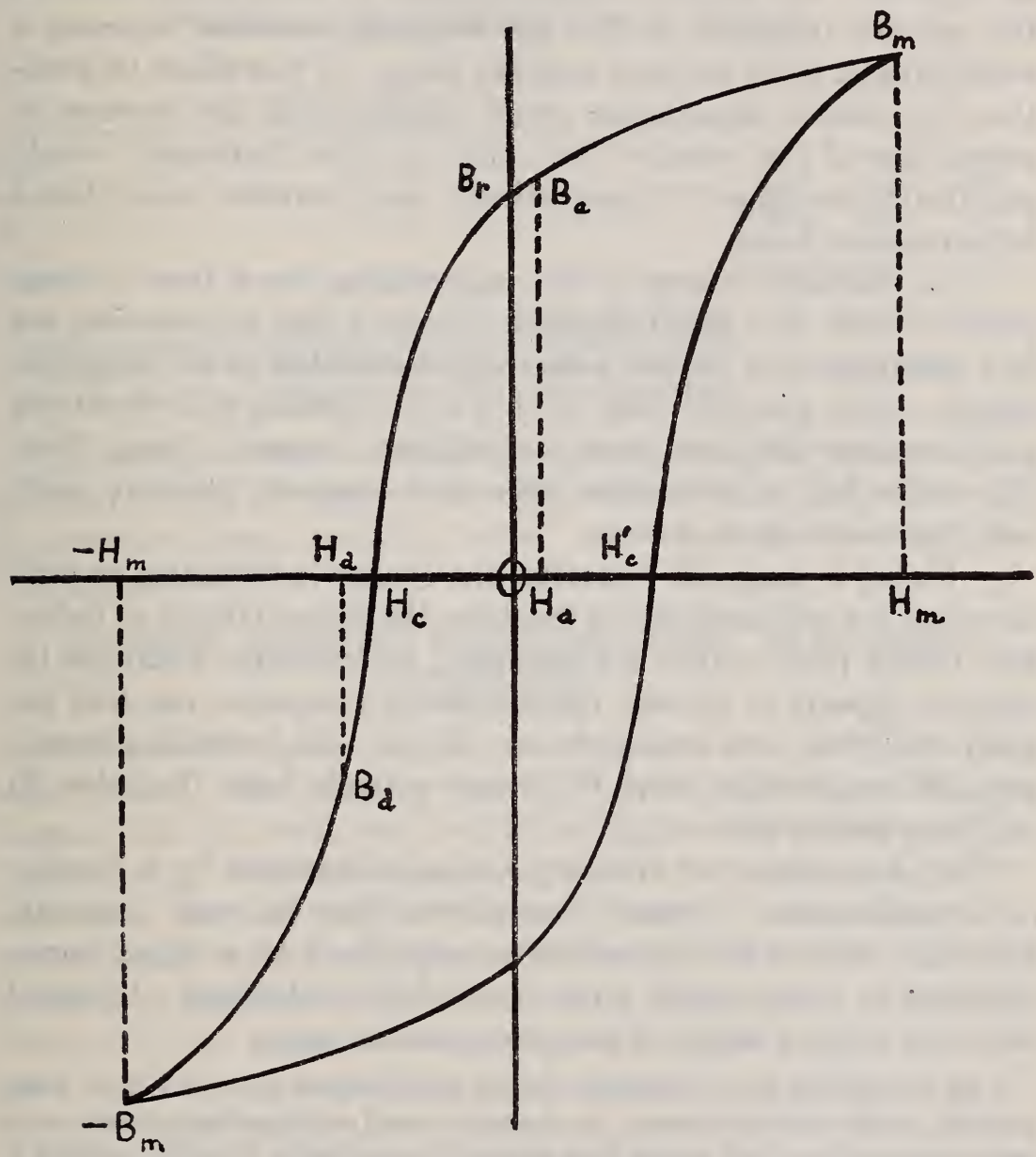

FIG. I.-Characteristic hysteresis loop

results obtained by the method herein described were found to be too large, the difference being very small in the case of magnetically hard material having a large coercive force, but being about Ioo per cent too large for very soft material.

4 Campbell and Dye, Inst. of Elec. Eng. Journ., 54, p. 35; x918.

C. W. Burrows, B. S. Bulletin, 6, p. 31, 1909; Scientific Pap er No. 217.

F. P. Fahy, Chem. \& Met. Eng., 19, pp. 247-250; I918. 


\section{POSSIBLE CAUSES OF ERRORS IN READING}

The differences in comparative values, described above, may be due to a number of causes.

I. Owing to the small residual magnetism in the core of the electromagnet, the coercive force may not change from $H_{\mathrm{c}}$ to $O$, as supposed, but may be carried beyond to some small value in the opposite direction, so that the resulting deflection indicates a value greater than the true coercive force. If this effect be additive, its relative importance would decrease with the increase in magnitude of the coercive force; that is, the discrepancy would practically disappear for magnetically hard material which has a large coercive force.

2. In suddenly changing the magnetizing force from a large positive value to a small negative value the field surrounding the test specimen may be less uniformly distributed in the space included within the test coils, so that upon opening the circuit the galvanometer deflection does not indicate a correct change from $H_{\mathrm{o}}$ to zero but to some other value and does not, therefore, indicate the true coercive force.

3. Owing to magnetic viscosity, the change in induction as indicated by the galvanometer is less than the actual change of induction taking place within the specimen; for example, when the induction appears to be zero (galvanometer deflection, one-half the total deflection for a change from $+B_{\mathrm{m}}$ to $-B_{\mathrm{m}}$ ) resulting from a negative magnetizing force $H_{\mathrm{c}}$ it may actually have the value $B_{\mathrm{d}}$ resulting from a force $H_{\mathrm{d}}$.

This phenomenon of viscosity has been described by a number of experimenters. Ewing ${ }^{7}$ has shown that in weak magnetic fields soft iron is not immediately magnetized to a degree corresponding to the magnetic force to which it is subjected. Jouaust, ${ }^{8}$ who has made a study of the phenomenon, says:

If the magnetizing field is suddenly changed from its value $+H$ to a value $h$, then, generally, as the result of viscosity, the deflection $\delta$ read on the ballistic galvanometer is weaker than that which should have appeared in conformity with the variation of flux which has been produced. And indeed, if, after having waited a few moments, the magnetizing field is varied from $h$ to $-H$, one observes a deflection $\delta_{2}$ such that $\delta+\delta_{2}$ is less than the deflection $\Delta$, observed in passing from $+H$ to $-H$. But if we shift the magnetic field from $h$ to $+H$ (corresponding to a condition of saturation), as the phenomenon of lag is not produced, the deflection $\delta_{1}$, read on the ballistic galvanometer, is a good indication of the variation of flux which has taken place, and which is equal to that which should have been measured; in which case, we have, as might be expected, $\delta_{1}+\delta_{2}=\Delta$.

\footnotetext{
${ }^{7}$ Ewing, Magnetic Induction in Iron and Other Mețals, p. I22.
}

8 Jouaust, Trans. Elec. Cong., St. Louis, 1, p. 470; 1904. 
Table $I$ is taken from Jouaust's paper. Column I gives the actual variations of flux produced $\left(\delta_{1}\right)$; column 2 , the variations estimated from the ballistic deflections when the variation is suddenly produced $\left(\delta_{3}\right)$; and column 3 , when this process is divided up into about I 5 successive operations, the value of the maximum of the field being in all cases 98 gausses.

TABLE 1.-Effect of Magnetic Viscosity (Jouaust)

\begin{tabular}{|c|c|c|c|}
\hline H (Gausses) & $a_{1}$ & b2 & $c 3$ \\
\hline 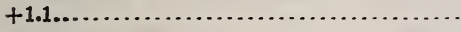 & 8000 & 7700 & 7650 \\
\hline 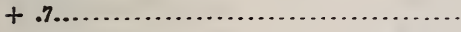 & 8720 & 8200 & 8300 \\
\hline 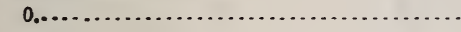 & 10500 & 9600 & 9850 \\
\hline 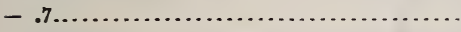 & 13700 & 11700 & 12200 \\
\hline 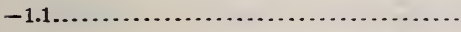 & 17850 & 13650 & 14750 \\
\hline
\end{tabular}

a Actual variations of flux produced in passing from $H$ to $H_{\max }=98$ gausses.

$b$ Variations estimated from ballistic deflections when variation is suddenly from $H_{\max }=98$ gausses.

$c$ Same as 2 , when process is divided up into about $x_{5}$ successive operations.

Very likely all three of the above causes are more or less contributory to the divergence of results obtained for the values of the coercive force, but the writer believes that the magnetic viscosity plays by far the most important rôle.

\section{PRESENT METHOD FOR MEASURING HYSTERESIS CONSTANTS}

The method for determining the coercive force, therefore, has been revised. Referring again to the hysteresis loop (Fig. I), suppose that the induction corresponding to a magnetizing force $H_{\mathrm{m}}$ is at $B_{\mathrm{m}}$. Let the magnetizing field be reversed and at the same time resistance added to the primary circuit so that the galvanometer deflection indicates a change of induction approximately one-half of the total change from $B_{\mathrm{m}}$ to $-B_{\mathrm{m}}$. As stated above, owing to magnetic viscosity, the induction may be at some point $B_{\mathrm{d}}$ while appearing from the galvanometer reading to be at $H_{\mathrm{c}}$. Now pass quickly from $B_{\mathrm{d}}$ to $-B_{\mathrm{m}}$ and back to $H^{\prime}{ }_{\mathrm{c}}$. If $B_{\mathrm{d}}$ and $H_{\mathrm{c}}$ coincide, the net change of induction in passing through the semicycle will be zero; but if $\mathrm{B}_{\mathrm{d}}$ and $H_{\mathrm{c}}$ do not coincide there will be observed a residual deflection of the galvanometer. By adjusting the auxiliary resistance, $B_{\mathrm{d}}$ and $H_{\mathrm{c}}$ can be made to coincide so that the net change in induction is zero. Going back to $H_{\mathrm{m}}$ and reducing to $H_{\mathrm{c}}$ it will be found that; if there is any effect due to viscosity, the ballistic galvanometer will indicate a value for the change in induction other than one-half the total 


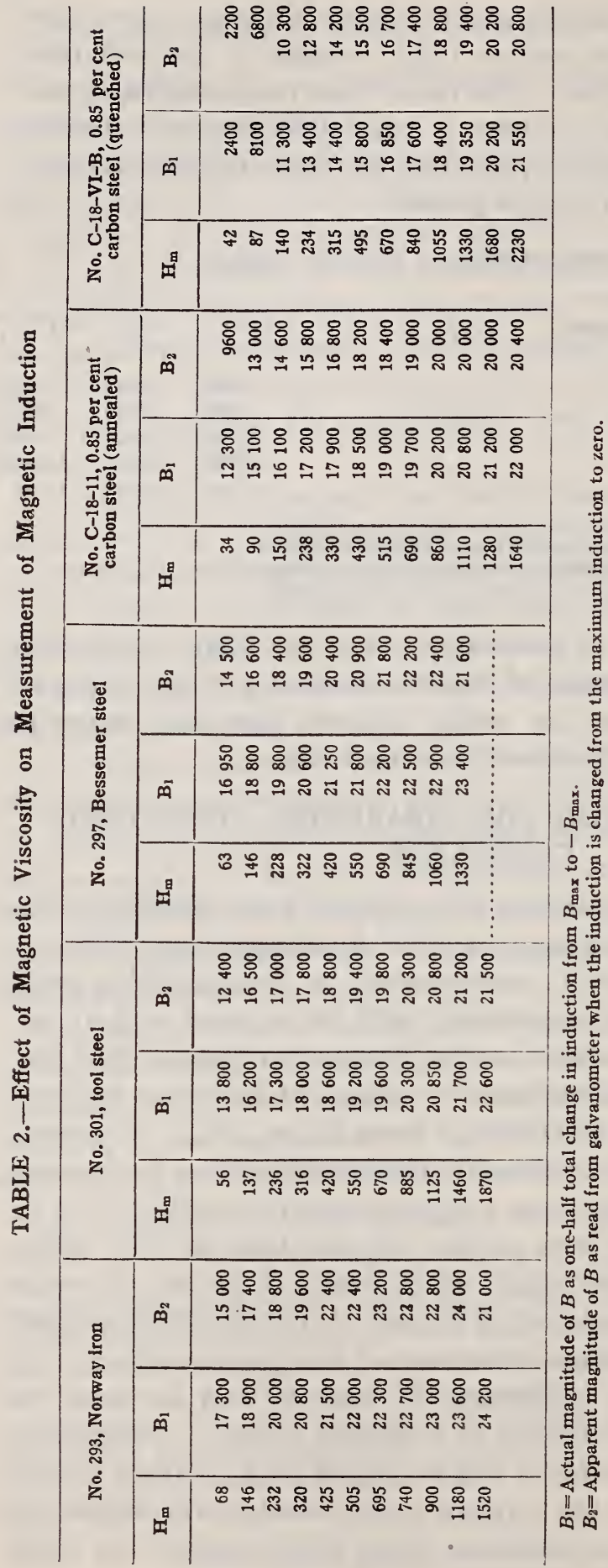


change from $B_{\mathrm{m}}$ to $-B_{\mathrm{m}}$. Table 2 gives for comparison values $\left(B_{2}\right)$ obtained in this manner and the actual values $\left(B_{1}\right)$ as obtained by taking one-half the deflection for complete reversal of $B$. It will be observed that the discrepancy decreases with the hardness of the material.

To accomplish the procedure just described a special gang switch has been devised so that one throw of the switch causes the induction to change from its maximum value to zero, and upon throwing back to change from zero to its maximum negative value and back again to zero. After this adjustment is made the process is repeated with the $H$ coils connected in series with the galvanometer. The coercive force which is one-half the change in $H$ from $H_{c}$ to $H^{\prime}{ }_{c}$ is then read directly.

\section{TABLE 3.-Coercive Force and Residual Induction as Obtained by Different} Apparatus

\begin{tabular}{|c|c|c|c|c|c|c|c|c|}
\hline \multirow[b]{2}{*}{$\begin{array}{l}\text { Sample } \\
\text { No. }\end{array}$} & \multirow[b]{2}{*}{ Material } & \multirow[b]{2}{*}{$\mathbf{H}_{\max }$} & \multicolumn{3}{|c|}{$\mathrm{H}_{0}$} & \multicolumn{3}{|c|}{$\mathbf{B}_{\tau}$} \\
\hline & & & $\begin{array}{l}\text { Burrows } \\
\text { perme- } \\
\text { ameter }\end{array}$ & $\begin{array}{l}\text { Fahy } \\
\text { perme- } \\
\text { ameter }\end{array}$ & \begin{tabular}{|c|} 
High \\
induction \\
apparatus
\end{tabular} & $\begin{array}{l}\text { Burrows } \\
\text { perme- } \\
\text { ameter }\end{array}$ & $\begin{array}{l}\text { Fahy } \\
\text { perme- } \\
\text { ameter }\end{array}$ & $\begin{array}{l}\text { High } \\
\text { induction } \\
\text { apparatus }\end{array}$ \\
\hline \multirow[t]{4}{*}{$293 . . . . .}$. & Norway iron........ & 100 & 1.61 & 2.4 & 1.5 & 8480 & 10000 & 10200 \\
\hline & & 150 & 1.70 & 2.5 & 2.0 & 8580 & 10400 & 11700 \\
\hline & & 200 & 1.75 & 2.8 & 2.0 & 8600 & 10700 & 12700 \\
\hline & & 250 & 1.72 & ........ & 2.0 & 8670 & .......... & 13200 \\
\hline \multirow[t]{4}{*}{$294 . .}$. & ....do. & 100 & 1.85 & 2.4 & 1.5 & 8250 & 9660 & 9850 \\
\hline & & 150 & 1.85 & 2.5 & 2.0 & 8250 & 10100 & 11000 \\
\hline & & 200 & 1.80 & 2.6 & 2.0 & 8250 & 10600 & 11950 \\
\hline & 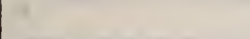 & 250 & 1.85 & ............ & ...... & 8250 & ........ & 12700 \\
\hline \multirow[t]{4}{*}{$297 . \ldots \ldots}$. & Bessemer steel... & 100 & 4.95 & 5. 2 & 5.0 & 11720 & 12500 & 11000 \\
\hline & & 150 & 5.0 & 5.4 & 5.0 & 11740 & 12600 & 12000 \\
\hline & & 200 & 5.0 & 5.6 & 5.5 & 11800 & 14900 & 12700 \\
\hline & & 250 & 5.05 & ....... & 5.5 & 11800 & ........ & 13200 \\
\hline \multirow[t]{4}{*}{$298 \ldots$} & .....do..... & 100 & 5.1 & 5.2 & 5.5 & 11500 & 12400 & 11300 \\
\hline & & 150 & 5.0 & 5.6 & 5.5 & 11500 & 12700 & 12400 \\
\hline & & 200 & 5.2 & 5.6 & 6.0 & 11500 & 13000 & 13000 \\
\hline & & 250 & 5.3 & ............ & 6.0 & ......... & ......... & 13400 \\
\hline \multirow[t]{4}{*}{$301 . . . \ldots}$. & Tool steel............... & 100 & 13.2 & 13.0 & 13.0 & 10900 & 11250 & 10400 \\
\hline & & 150 & 13. 3 & 13.0 & 13.5 & 11350 & 11800 & 11300 \\
\hline & & 200 & 13.5 & 13.4 & 14.0 & 11500 & 12000 & 11800 \\
\hline & & 250 & 13.9 & ........... & 14.0 & 11600 & …...... & 12100 \\
\hline \multirow[t]{4}{*}{$302 .}$. & .....do......... & 100 & 12. 0 & 11.6 & 12.5 & 11000 & 11300 & 10000 \\
\hline & & 150 & 12.5 & 12. 3 & 13.5 & 11350 & 11800 & 10900 \\
\hline & 10 & 200 & 12.9 & 12.6 & 14.0 & 11500 & 12000 & 11400 \\
\hline & 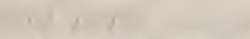 & 250 & 12.9 & ...... & 15.0 & 11700 & ............ & ......... \\
\hline \multirow[t]{6}{*}{ C-18-VI.. } & $\begin{array}{l}0.85 \text { per cent carbon } \\
\text { steel, quenched in }\end{array}$ & 200 & ........... & 42.8 & 45.0 & $\ldots \ldots \ldots$ & 7990 & 7700 \\
\hline & oil. & 1 & in & & & & we & \\
\hline & 0.85 per cent carbon & 100 & 44 & 42 & 42 & 6070 & 6200 & 6200 \\
\hline & steel, quenched in & 150 & 48 & 46 & 44 & 7180 & 7250 & 6700 \\
\hline & water. & 200 & 50 & 48 & 49 & 7520 & 7750 & 7700 \\
\hline & & 250 & 53 & 49 & 52 & 7620 & 7800 & 8000 \\
\hline
\end{tabular}


Table 3 gives values obtained in this manner (column 6) and compared with those obtained by the Burrows permeameter (column 4) and the Fahy permeameter (column 5). It will be observed that within the experimental error the values agree favorably. The observations in column 6 , however, could not be read to as high precision as those in columns 4 and 5 .

Since there is this favorable comparison for low magnetizing forces, it may be assumed that results are correct for high field values also.

As regards the measurement of the residual induction, it was concluded after repeated trials that, owing to errors inherent in the methods, the method already in use could not be improved

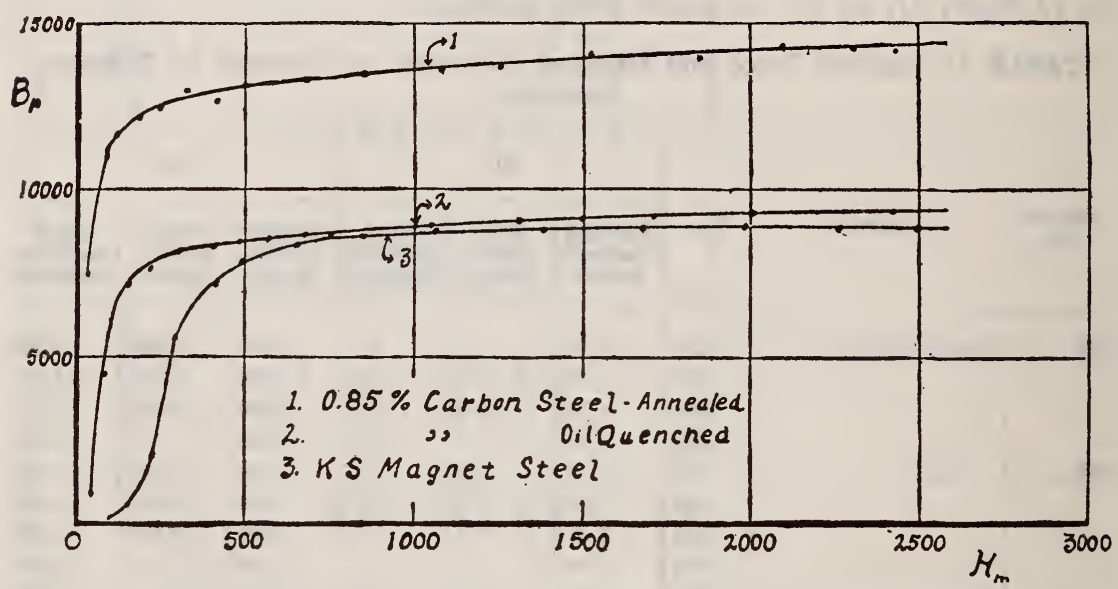

Fig. 2.-Variation of residual induction with magnetizing force for three specimens of steel

upon. For soft materials the values are too high, but for harder materials they vary only slightly from the true value. In Table 3 , columns 7,8 , and 9 , are shown the residual induction as obtained by the three types of apparatus.

In Fig. 2, the residual inductions, and in Fig. 3, the coercive forces for successive maximum magnetizing forces up to $H=2500$ are shown graphically for three particular specimens, viz, eutectoid steel ( 0.85 per cent carbon) in the annealed condition, same steel when quenched in oil, and a remarkable magnet steel known as K S magnet steel and prepared by Prof. Honda. It will be observed that both curves resemble in shape the intensity of magnetization curve. 


\section{SUMMARY}

This paper consists primarily of a discussion of:

I. An earlier attempt to measure hysteresis values by means of a modification of the "isthmus method" and described by the writer in a former paper.

2. Possible causes for discrepancies which appeared in the results as compared with those obtained on other types of apparatus.

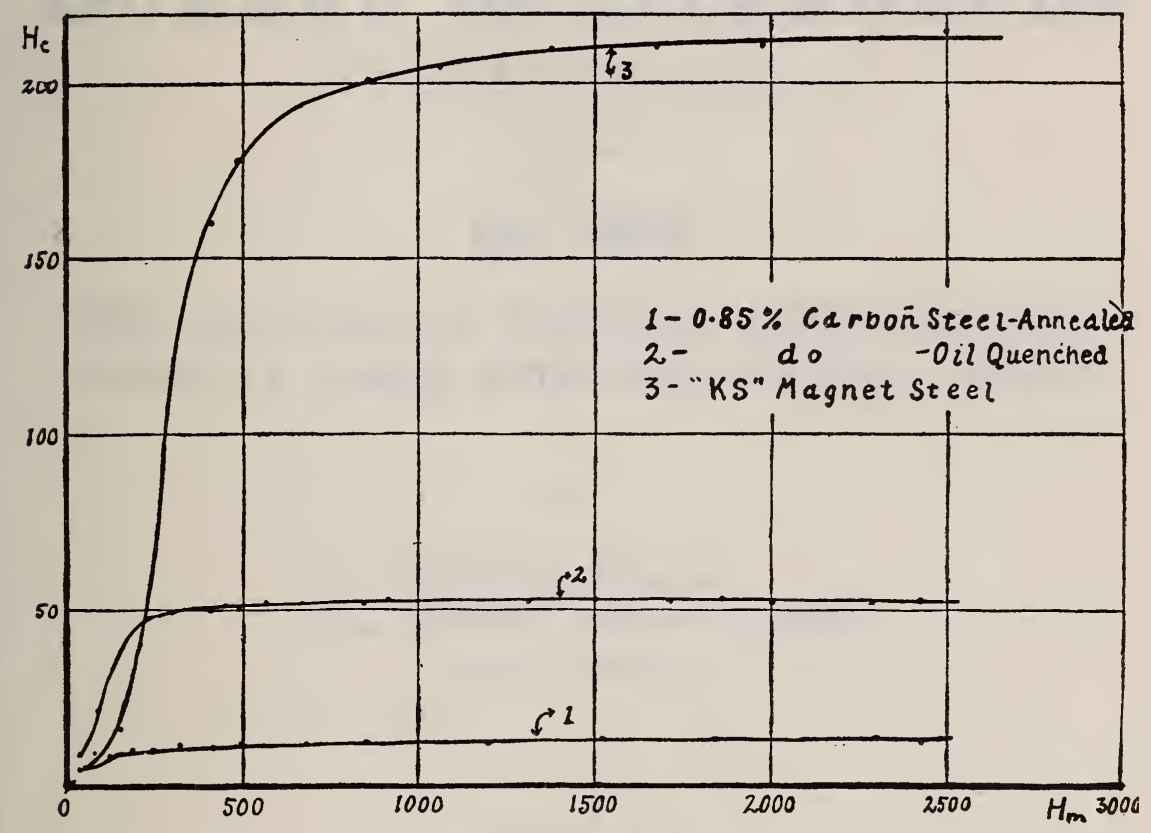

FIG. 3.-Variation of coercive force with magnetizing force for three specimens of steel

3. A new method of measuring the coercive force by means of this same apparatus.

Graphs are given which show the coercive forces and the residual inductions from successively higher maximum magnetizing forces plotted against the latter as the independent variable up to a field of $H=2500$ gausses.

WAShington, March 29, 1920. 